\title{
Integrated consensus genetic and physical maps of flax (Linum usitatissimum L.)
}

\author{
Sylvie Cloutier $\cdot$ Raja Ragupathy $\cdot$ Evelyn Miranda • \\ Natasa Radovanovic • Elsa Reimer • Andrzej Walichnowski • \\ Kerry Ward · Gordon Rowland · Scott Duguid • Mitali Banik
}

Received: 28 March 2012/ Accepted: 21 July 2012/Published online: 14 August 2012

(C) The Author(s) 2012. This article is published with open access at Springerlink.com

\begin{abstract}
Three linkage maps of flax (Linum usitatissimum L.) were constructed from populations CDC Bethune/ Macbeth, E1747/Viking and SP2047/UGG5-5 containing between 385 and 469 mapped markers each. The first consensus map of flax was constructed incorporating 770 markers based on 371 shared markers including 114 that were shared by all three populations and 257 shared between any two populations. The 15 linkage group map corresponds to the haploid number of chromosomes of this species. The marker order of the consensus map was largely collinear in all three individual maps but a few local inversions and marker rearrangements spanning short intervals were observed. Segregation distortion was present in all linkage groups which contained 1-52 markers
\end{abstract}

Communicated by R. Visser.

Electronic supplementary material The online version of this article (doi:10.1007/s00122-012-1953-0) contains supplementary material, which is available to authorized users.

S. Cloutier $(\varangle) \cdot$ R. Ragupathy · E. Miranda ·

N. Radovanovic · E. Reimer - A. Walichnowski .

K. Ward · M. Banik

Cereal Research Centre, Agriculture and Agri-Food Canada, 195 Dafoe Road, Winnipeg, MB R3T 2M9, Canada

e-mail: sylvie.j.cloutier@agr.gc.ca

S. Cloutier

Department of Plant Science, University of Manitoba,

66 Dafoe Road, Winnipeg, MB R3T 2N2, Canada

G. Rowland

Crop Development Centre, University of Saskatchewan,

51 Campus Drive, Saskatoon, SK S7N 5A8, Canada

S. Duguid

Morden Research Station, Agriculture and Agri-Food Canada, 101 Route 100, Unit 100, Morden, MB R6M 1Y5, Canada displaying non-Mendelian segregation. The total length of the consensus genetic map is $1,551 \mathrm{cM}$ with a mean marker density of $2.0 \mathrm{cM}$. A total of 670 markers were anchored to 204 of the 416 fingerprinted contigs of the physical map corresponding to $\sim 274 \mathrm{Mb}$ or $74 \%$ of the estimated flax genome size of $370 \mathrm{Mb}$. This high resolution consensus map will be a resource for comparative genomics, genome organization, evolution studies and anchoring of the whole genome shotgun sequence.

\section{Introduction}

Flax (Linum usitatissimum L., $2 n=2 x=30$ ), is an annual self-pollinated crop that is commercially grown as a source of stem fibre and seed oil. Flax seed oil is utilized for the fabrication of various biodegradable products such as high quality drying oil, paints, varnishes and linoleum flooring. Flax oil is a rich source of omega-3 fatty acids used as nutraceuticals and also as a functional food for both humans and animals. Fibre and oilseed flax belong to the same species but are morphologically different. Oilseed type flax plants (linseed) are more branched and shorter than the fibre type (Gill 1987). Fibre flax is grown mainly in Northern Europe, Russia and China but linseed is the primary type grown in Canada, USA, Argentina and India as well as Russia and China (Gill 1987; Marchenkov et al. 2003).

Development and characterization of flax genetic resources and assessment of genetic variability are essential for germplasm conservation and breeding. Flax germplasm collections contain thousands of accessions of L. usitatissimum and related species, of which, subsets were assessed for the extent of genetic diversity for morphological characteristics (Diederichsen and Hammer 1995; Diederichsen 2001; Diederichsen and Raney 2006; 
Saeidi 2008). A variety of molecular markers including random amplified polymorphic DNA (RAPD), restriction fragment length polymorphism (RFLP), amplified fragment length polymorphism (AFLP) and simple sequence repeat (SSR) have been developed and used in assessing flax genetic diversity (Spielmeyer et al. 1998; Oh et al. 2000; Wiesner et al. 2001; Fu et al. 2003; Adugna et al. 2006; Fu 2006, Roose-Amsaleg et al. 2006; Cloutier et al. 2009, 2012; Uysal et al. 2010; Deng et al. 2010, 2011; Bickel et al. 2011; Kale et al. 2012; Rachinskaya et al. 2011; Soto-Cerda et al. 2011a, 2011b). While the reports are numerous, the number of informative markers in each of the studies is somewhat limited with the majority reporting between 9 and 60 markers only (Cloutier et al. 2012).

SSRs are stretches of DNA consisting of a variable number of short tandem repeats that are generally codominant, highly polymorphic, multi-allelic, relatively abundant, heritable, reproducible and reliable (Powell et al. 1996; Hwang et al. 2009). They also show cross-species usefulness and can be used in closely related species (Powell et al. 1996; Collard et al. 2005; Varshney et al. 2005). SSRs have been developed from genomic sequences or Expressed Sequence Tags (ESTs). In flax, Ragupathy et al. (2011) identified 4,064 putative SSRs from bacterial artificial chromosome (BAC) end sequences (BES). SSR markers have also been developed from various flax EST libraries (Cloutier et al. 2009; Soto-Cerda et al. 2011b) and from SSR-enriched genomic libraries or other genomic sequences (Roose-Amsaleg et al. 2006; Deng et al. 2010, 2011; Bickel et al. 2011; Kale et al. 2012; Rachinskaya et al. 2011). There are currently 1,326 SSR markers published in flax (Cloutier et al. 2012). SSR markers have been used for the construction of genetic maps of many plant species and provide dependable landmarks throughout the genome (Cheng et al. 2009; Studer et al. 2010). In flax, genetic maps and genetic diversity assessment were achieved with this type of marker (Fu and Peterson 2010; Cloutier et al. 2011; Soto-Cerda et al. 2011b). Genetic maps are useful for evolutionary and comparative studies as they provide both intra- and inter-species genome wide insights on recombination rates and gene rearrangements within or across chromosomes (Ball et al. 2010; Wang et al. 2011).

Only three individual flax linkage maps (Spielmeyer et al. 1998; Oh et al. 2000; Cloutier et al. 2011) have been published to date. The linkage map developed by Cloutier et al. (2011) had 113 markers, mostly SSRs, grouped into 24 linkage groups, while those of Spielmeyer et al. (1998) and Oh et al. (2000) were based on 213 AFLP markers forming 18 linkage groups and 94 RFLP/RAPD markers grouped into 15 linkage groups, respectively. The limitations of these maps reside in either or both the type and limited number of markers. Hence the need exists for a reliable, high density genetic map of flax that would serve as reference for a wide variety of applications such as QTL mapping, map based gene cloning, marker assisted crop improvement, linkage disequilibrium (LD) mapping, phylogenetic analysis and anchoring of the whole genome shotgun sequence assembly. Consensus genetic linkage maps have been constructed for various plant species including Arabidopsis (Hauge et al. 1993), Brassica (Xu et al. 2010, Wang et al. 2011), barley (Langridge et al. 1995; Varshney et al. 2007), sorghum (Mace et al. 2009), wheat (Somers et al. 2004), rice (Antonio et al. 1996), maize (Cone et al. 2002), red clover (Isobe et al. 2009), lettuce (Truco et al. 2007), rye (Gustafson et al. 2009), soybean (Hwang et al. 2009), melon (Diaz et al. 2011), grapevine (Vezzulli et al. 2008), cowpea (Muchero et al. 2009), chickpea (Millan et al. 2010), potato (Danan et al. 2011), eucalyptus (Brondani et al. 2006), Cucurbita pepo (Zraidi et al. 2007) and Zoysia species (Li et al. 2010). High density consensus maps are well suited as references for the incorporation of information from genetically diverse individuals or multiple populations thus facilitating comparative analyses across germplasm.

Whole genome physical maps have been constructed for maize (Messing et al. 2004), Brachypodium (Gu et al. 2009), melon (González et al. 2010), grapevine (Scalabrin et al. 2010), Arabidopsis (Mozo et al. 1999), Brassica rapa (Mun et al. 2008), soybean (Wu et al. 2004), apple (Han et al. 2011) and flax (Ragupathy et al. 2011). BAC-based physical maps have been anchored to genetic maps in a number of plants such as rice (Chen et al. 2002), maize (Wei et al. 2009), papaya (Yu et al. 2009), Medicago (Mun et al. 2006), bean (Córdoba et al. 2010), poplar (Kelleher et al. 2007), grapevine (Scalabrin et al. 2010) and melon (González et al. 2010), where they were used to order physical maps and provide a framework for genome sequence assemblies.

The physical map of the flax genome cv. CDC Bethune, an oilseed flax variety, consists of 416 fingerprinted contigs (FPC) spanning $\sim 368 \mathrm{Mb}$, very close to the estimated genome size of CDC Bethune of approximately $370 \mathrm{Mb}$ (Ragupathy et al. 2011). The present study was intended to: (1) construct three independent genetic maps, (2) create an integrated consensus genetic map and (3) anchor the consensus genetic and physical maps of flax to provide the backbone information for ordering the whole genome shotgun (WGS) sequence assembly.

\section{Materials and methods}

Plant material, DNA extraction and marker amplification

Three segregating populations were used for mapping. CDC Bethune/Macbeth (BM) is comprised of $243 \mathrm{~F}_{6^{-}}$ 
derived recombinant inbred lines (RILs). The two parents are current varieties termed 'conventional' oilseed types because they contain 55-57 \% linolenic acid, a "standard" amount for oilseed flax varieties. E1747/Viking (EV) received from S. Knapp (University of Georgia, USA) consists of $90 \mathrm{~F}_{6}$-derived RILs generated from a cross between the low linolenic acid line E1747 and the European fibre flax variety Viking. SP2047/UGG5-5 (SU) is an $\mathrm{F}_{1}$-derived doubled haploid $(\mathrm{DH})$ population of 78 individuals. SP2047 is a solin breeding line characterized by its 2-4\% linolenic acid content and yellow seeds while UGG5-5 is a "high-lin" line with 65-70 \% linolenic acid (Banik et al. 2011; Cloutier et al. 2011).

Genomic DNA was extracted from lyophilized leaf tissue ( $\sim 100 \mathrm{mg}$ fresh) of individual seedlings of all the segregating and parental lines of the three mapping populations using the DNeasy 96 plant kit according to manufacturer's instructions (Qiagen Inc, Toronto, ON, Canada). The genomic DNA was quantified by fluorometer and resuspended to a final concentration of $6 \mathrm{ng} / \mu \mathrm{l}$. Amplification of template DNA with SSR primers was performed in 384well plates in a final volume of $10 \mu \mathrm{l}$. The amplification products were resolved on an ABI 3130xl Genetic analyzer (Applied Biosystems, Foster City, CA, USA) and scored for segregation of parental alleles at each SSR locus. A total of five SNPs and seven genes ( $f a d 2 A, f a d 2 B, f a d 3 A, f a d 3 B$, $\operatorname{dgat} A, \operatorname{dgat} B$ and $y s c 1)$ were also positioned on the maps (Cloutier et al. 2011). Protocols and primer information for SSR markers Lu4 to Lu1193, Lu2097 to Lu2300 and Lu2331 to Lu3291 were previously described (Cloutier et al. 2009, 2011, 2012). In addition, SSR markers Lu2001 to Lu2096 were from previously published reports (RooseAmsaleg et al. 2006; Deng et al. 2010, 2011) while Lu2301 to Lu2330 were designed from scaffold 505 of the flax WGS sequence assembly (http://www.phytozome.net), as previously described (Cloutier et al. 2009, 2012). References for individual markers of the consensus map are listed (Supplementary Table S1).

Anchoring the genetic and physical maps

Genetic and physical map anchoring was performed using complementary strategies. First, the CDC Bethune BAC library was screened with a subset of the SSR primers positioned on the genetic maps to identify BAC addresses and their corresponding FPC contigs (Ragupathy et al. 2011). SSR markers Lu2097-Lu2300 and Lu2331-Lu3291 were derived directly from BESs and, as such, were directly assigned BAC addresses and corresponding FPC contigs. These BES anchors were confirmed by performing BLASTn searches of the SSR primer sequences against the flax WGS sequence assembly (http://www.phytozome.net). Only perfect matches of both primer sequences to the same scaffold were considered for anchoring. BLASTn searches were also performed using the BESs from which the SSRs were derived and matches with an $e$ value $<1 \mathrm{e}-25$ were considered scaffold anchors. Similarly, primer BLAST and BLASTn were performed for SSR markers Lu4 to Lu1193 derived from ESTs (Cloutier et al. 2009, 2012). The marker name convention "marker name_FPC contig number" (e.g. Lu3156_405) was adopted to indicate positioning of the markers on the physical map. Markers not anchored to an FPC contig were labelled '0' (e.g. Lu2312_0). Markers amplifying two or three loci were labelled with a single contig number but likely belong to paralogous contigs.

Map construction and linkage analysis

Linkage analysis was carried out independently for each mapping population using JoinMap 4.0 (Van Ooijen 2006) with a LOD of 4.0 and a maximum recombination frequency of 40. Marker segregation was tested against the expected Mendelian ratio of 1:1 using the Chi-square goodness-of-fit test. For conversion of recombination frequency into map distances expressed in centiMorgans (cM), the Kosambi mapping function which accounts for genetic interference from double cross over was used (Kosambi 1944).

The consensus linkage map was constructed based on the principle illustrated by Stam (1993) using JoinMap 4.0 (Van Ooijen 2006). LOD scores and pairwise recombination frequencies were computed for all linkage groups (LGs) of individual populations. They were then combined into a single group node in the navigation tree using the 'grouping node' command. Consensus LGs were obtained using the 'combine groups for map integration' function that is based on the presence of a minimum of two marker loci common to at least two populations on the basis of the mean recombination frequencies and combined LOD scores of pairwise data from the three segregating populations. The consensus map was constructed according to Alheit et al. (2011) and Gong et al. (2008) using the following parameters: Kosambi mapping function, regression mapping option, maximum recombination frequency of 40 , LOD $>1.0$, ripple $=1$, third round $=$ yes and goodness-offit jump threshold for removal of loci $=5.0$. Comparative analyses of marker distance and marker order were performed across individual maps and with the consensus map by visualization of the four final maps obtained as described above. The individual homologous LGs from the three populations were integrated using commonly mapped markers based on 411 segregating lines (243 RILs from BM, 90 RILs from EV and 78 DHs from SU). The 15 consensus LGs were numbered LG1 to LG15, in decreasing size order (cM). The population specific LGs were described using the population acronyms and the same 
number as in the consensus map (BMLG1-BMLG16, EVLG1-EVLG18 and SULG1-SULG15).

\section{Results}

Individual genetic linkage maps

\section{CDC Bethune/Macbeth}

A total of 389 segregating marker loci were polymorphic in the BM population, of which, 385 marker loci assembled into 16 LGs spanning 2,007 cM, for an average density of one marker locus every $5.2 \mathrm{cM}$, and 4 marker loci remained unlinked (Table 1). LGs ranged from 27 to $187 \mathrm{cM}$ and contained 9-40 markers. The dgatA and dgatB genes were mapped in this population. The population showed segregation distortion for 56 loci $(P<0.05)$ with equal numbers of loci skewed towards each parent (Supplementary Table S2).

\section{E1747/Viking}

The EV population was assayed with 443 polymorphic marker loci, 442 of which grouped into 18 LGs leaving a single marker unlinked (Table 1). The length of the LGs and number of marker loci per LG varied from 10 to $168 \mathrm{cM}$ and 2-46, respectively. The total length of the map was $1,731 \mathrm{cM}$ with a mean marker density of $3.9 \mathrm{cM}$ between loci. 77 of the 442 loci diverged significantly from the expected 1:1 segregation ratio with 33 skewed towards E1747 and 44 skewed towards Viking (Supplementary Table S2).

\section{SP2047/UGG5-5}

The previously published SU map was based on 125 marker loci assembled in 24 linkage groups spanning
$834 \mathrm{cM}$ (Cloutier et al. 2011). The SU map constructed herein is more saturated and comprehensive with 477 polymorphic marker loci, of which 8 remained unlinked and the remaining 469 formed 15 LGs totalling $3,044 \mathrm{cM}$ (Table 1). The length of the LGs and the number of loci per LG varied from 136 to $362 \mathrm{cM}$ and $20-47$, respectively. The approximate average marker density was one every $6.5 \mathrm{cM}$. A total of 168 loci showed segregation distortion (Supplementary Table S2). All LGs contained distorted markers except SULG13 which contained a single polymorphic marker in the SU population and SULG14 (Supplementary Table S2). A total of seven genes including six from fatty acid biosynthetic pathways (fad $2 A, f a d 2 B, f a d 3 A, f a d 3 B, d g a t A$ and dgatB) were also mapped.

\section{Consensus map}

A total of 795 markers generated 821 loci for a locus per marker ratio of 1.03 because 18 markers identified two loci and four markers identified three loci. Of the 821 loci scored in the three populations, 114 were common to all three populations and another 257 were common to two of the three populations (Supplementary Table S3). A total of 770 marker loci were assembled into the 15 LGs constituting the consensus map (Fig. 1; Table 1). Four additional LGs contained 19 marker loci ordered based on a single mapping population and 32 markers remained unlinked (Table 1; Supplementary Table S2). The total length of the consensus genetic linkage map was $1,551 \mathrm{cM}$ and LGs ranged from 60 to $170 \mathrm{cM}$. The consensus map had an average marker density of one per $2.0 \mathrm{cM}$. Assuming a genome size of $370 \mathrm{Mb}$ for CDC Bethune (Ragupathy et al. 2011), the genome wide ratio of physical to genetic distance averaged $239 \mathrm{~Kb} / \mathrm{cM}$, equivalent to an average of one marker per $481 \mathrm{~Kb}$.

The length of the consensus map was shorter than the individual population specific maps (Table 1). All LGs of

Table 1 Mapping statistics for the three individual and the consensus genetic maps of flax

\begin{tabular}{lllllllll}
\hline Populations & $\begin{array}{l}\text { No. } \\
\text { individuals }\end{array}$ & $\begin{array}{l}\text { Total no. } \\
\text { marker loci }\end{array}$ & $\begin{array}{l}\text { No. marker } \\
\text { loci in LGs }\end{array}$ & $\begin{array}{l}\text { Length } \\
(\mathrm{cM})\end{array}$ & $\begin{array}{l}\text { No. } \\
\text { LGs }^{\mathrm{a}}\end{array}$ & $\begin{array}{l}\text { No. unlinked } \\
\text { marker loci }\end{array}$ & $\begin{array}{l}\text { No. marker loci in } \\
\text { the consensus map }\end{array}$ & $\begin{array}{l}\text { Percent marker loci } \\
\text { in the consensus map }\end{array}$ \\
\hline $\begin{array}{l}\text { CDC Bethune/ } \\
\quad \begin{array}{l}\text { Macbeth (BM) } \\
\text { E1747/Viking (EV) }\end{array}\end{array}$ & 243 & 389 & 385 & 2,007 & 16 & 4 & 373 & 95.9 \\
SP2047/UGG5-5 (SU) & 78 & 443 & 442 & 1,731 & 18 & 1 & 419 & 94.6 \\
Consensus & 411 & 821 & $770(19)$ & 1,551 & $15(4)$ & 32 & 763 & 97.1 \\
\hline
\end{tabular}

a Numbers in brackets represent marker loci and LGs belonging to a single population and that did not incorporate in the 15 LGs of the consensus map 
Fig. 1 Consensus genetic map of flax integrated from three mapping populations. Numbers to the left of each linkage group represent Kosambi map units (cM). Locus names followed by their FPC contig anchor separated by an underscore are on the right. Linkage groups are in decreasing size order
LG1

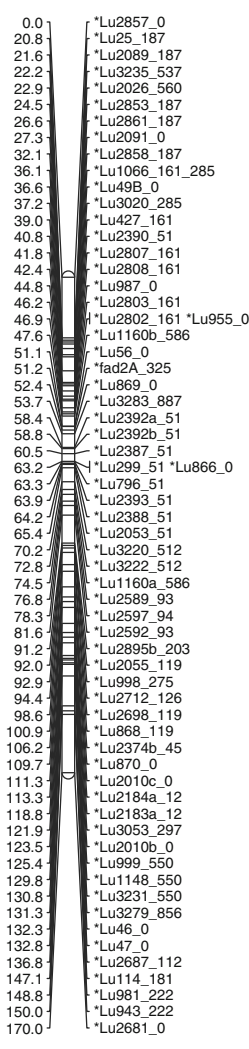

LG5

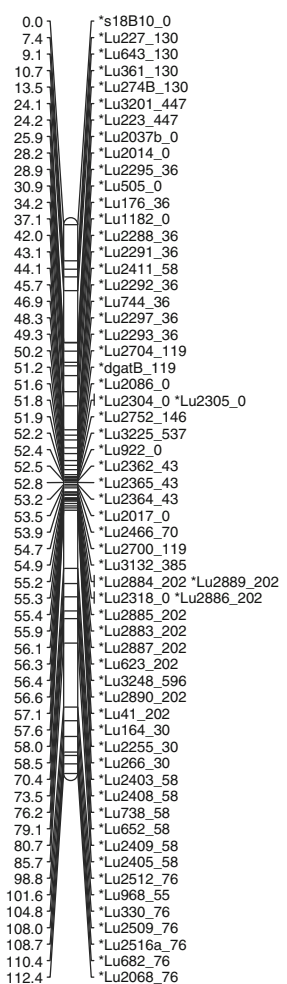

LG2

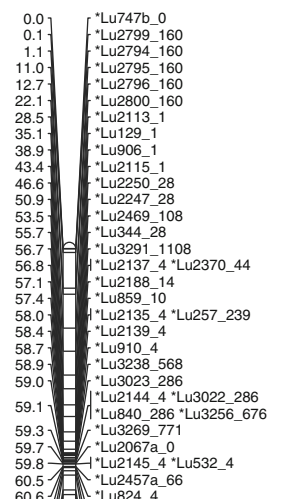

50.8

60.6 . Lu

62.9.

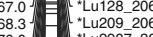

7.5 .5
77.3
71.3

72.4.

78.0
82.0

82.5
83.5

85.9 .

87.8
89.1
99.5
99.1
99.2

105.0 . L L

105.8.

106.5
109.2
113.3
137.5

$\left.\begin{array}{l}113.3 \\ 122.9 \\ 137.5\end{array}\right] \begin{array}{lll}\text { "Lu2720-134 } \\ \text { "Lu3205-475 }\end{array}$

LG6

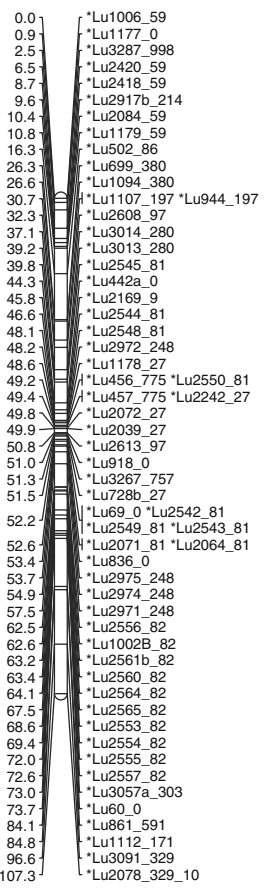

LG3

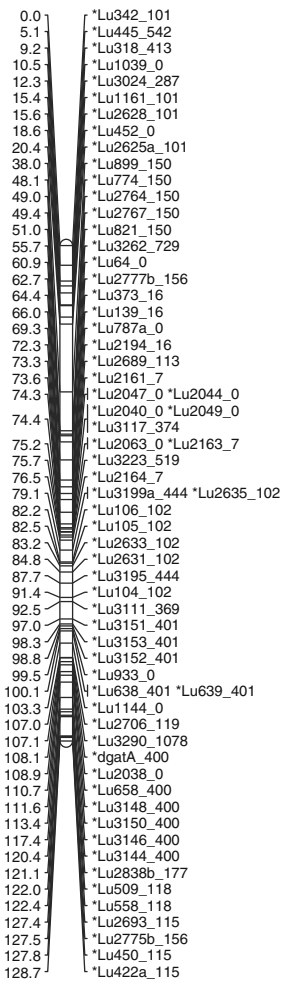

LG7

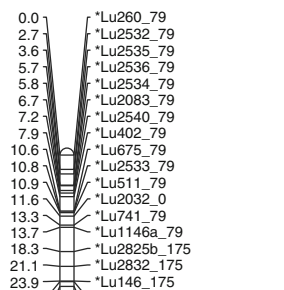

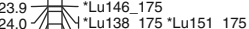

24.9 :LL235-230

28.8
3.2

$\left.\begin{array}{l}30.2 \\ 40.8\end{array}\right)$. Lul1818-436

42.3
42.7

$\left.\begin{array}{l}43.4 \\ 44.1\end{array}\right]$ 政

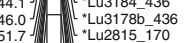

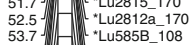

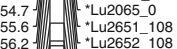

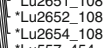

[Lu557_454

"Lu1124_-84

CLu2571_84
LLu2658 108
Lu2648_108

. Lu2648-108
"fad3A 84
"Lu44E-8 84

-Lu44E4_84
- Lu2003_281
-40566281

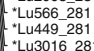

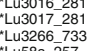

LG4

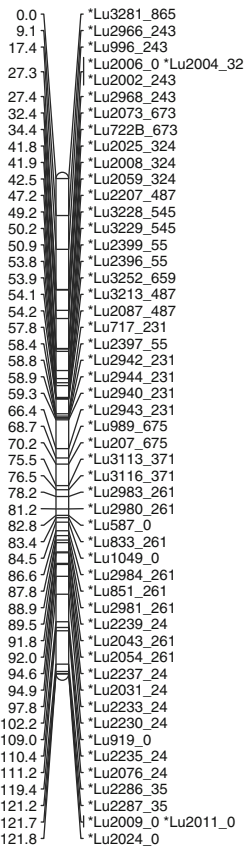

LG8

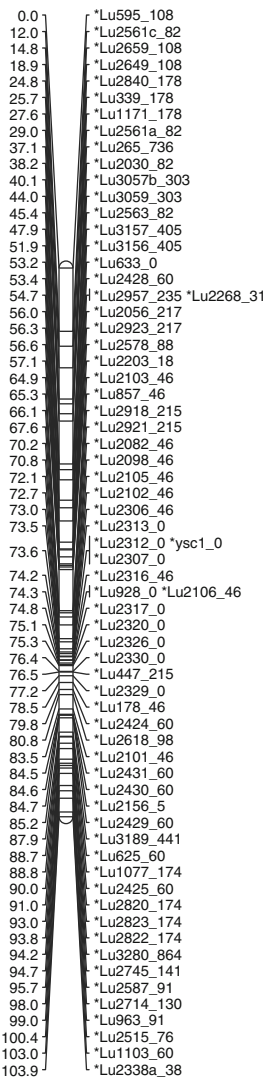


Fig. 1 continued

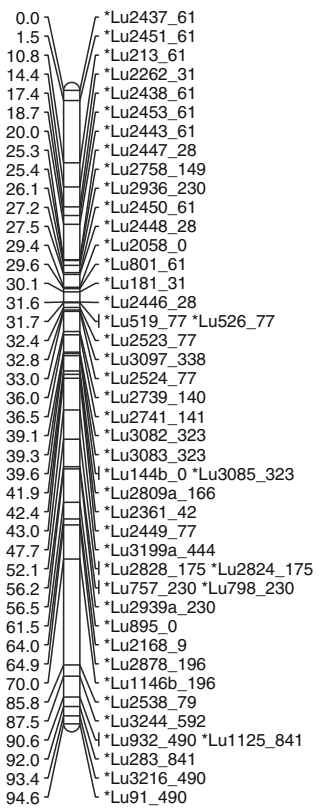

LG13

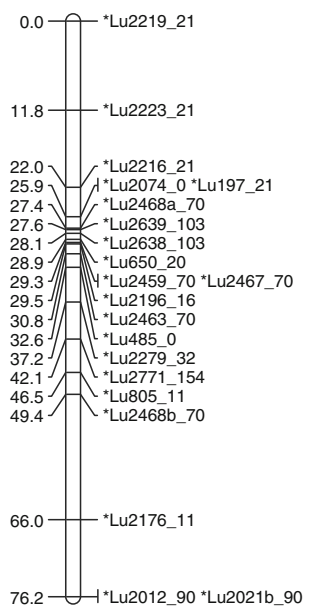

LG10

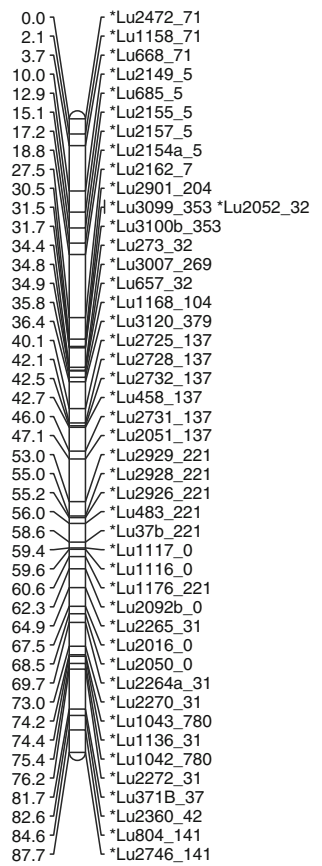

LG14

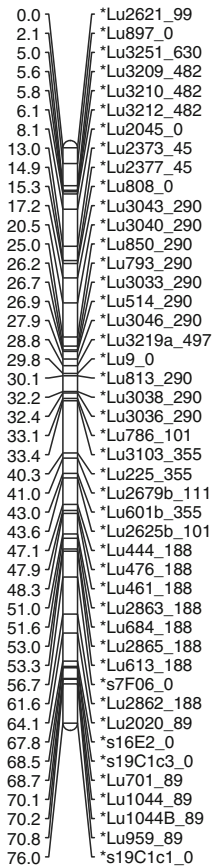

LG11

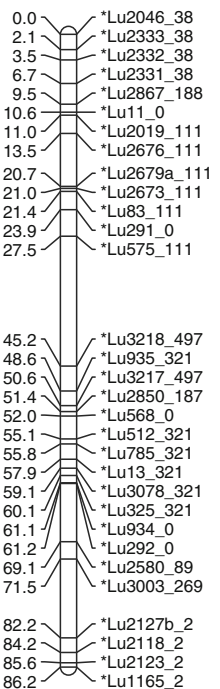

LG15

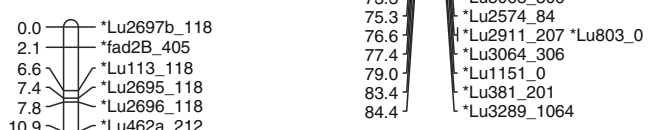

LG12

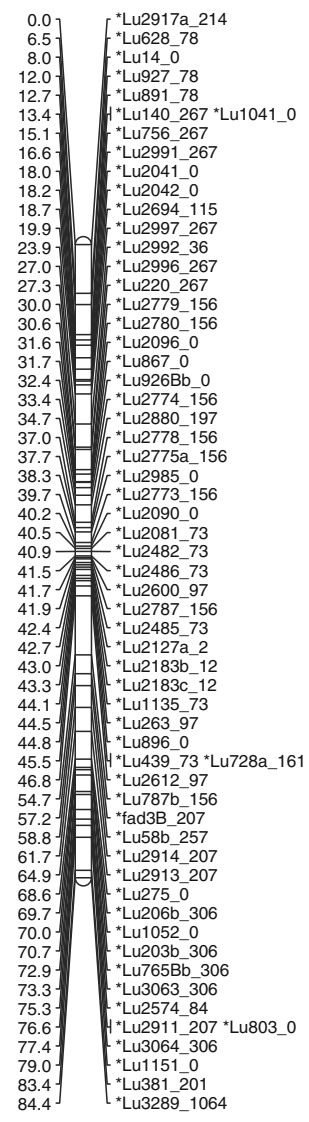

the consensus map were constructed based on markers shared among the three populations except LG13 which was constructed mostly with markers from the BM and EV populations because all markers, with the exception of Lu850, were monomorphic in the SU population. The consensus map displayed a few gaps that were mostly smaller than $10 \mathrm{cM}$. The largest gap of $20.8 \mathrm{cM}$ is in LG1 (Fig. 1; Supplementary Table S1). The marker orders were consistent between the three independent genetic maps with some local inversions. 
The percentages of distorted loci in BM, EV and $\mathrm{SU}$ populations were 15,17 and $36 \%$, respectively (Supplementary Table S2). Out of the 770 loci of the consensus map, $292(38 \%)$ loci exhibited segregation distortion in at least one of the three mapping populations (Supplementary Table S2). The presence of a large number of distorted loci seems to have caused the large gap in LG11. Although LG8 carried the most distorted loci (76\%), the length of that LG was not affected as compared to the bi-parental populations where marker segregation was Mendelian, although some local rearrangements of closely linked markers were observed. Overall, only a few ambiguities were identified with respect to marker position compared to individual maps. Markers Lu359_0 and Lu2354_40, common to all three populations, mapped at the proximal end of each individual population LG15. However, these markers were placed at internal positions (41.977 and $42.829 \mathrm{cM}$ ) in the consensus LG15 (Supplementary Table S1).

Anchoring genetic and physical maps

Of the 770 loci in the consensus genetic map, 670 were anchored to 204 of the 416 FPC contigs of the physical map (Ragupathy et al. 2011) corresponding to $274 \mathrm{Mb}$ or $74 \%$ of the flax genome (Fig. 2). Twenty-one of the 204 FPC contigs were anchored at more than one map location because some markers amplified two or three polymorphic loci (labelled with a small a, b or c suffix in Fig. 1). FPC contigs were anchored with 1-14 markers. Examples of FPC contigs anchored with 14 markers include FPC contigs 79 and 82 estimated at $2.836 \mathrm{Mb}$ with $205 \mathrm{BAC}$ clones and $3.192 \mathrm{Mb}$ with $265 \mathrm{BAC}$ clones, respectively. The largest FPC contig (21), estimated at $5.562 \mathrm{Mb}$, consisted of $437 \mathrm{BAC}$ clones and was anchored with four markers. Sixty-seven FPC contigs contained a single marker.

\section{Discussion}

Comparison of individual and consensus maps

Three genetic maps of flax have been published to date: a 213 AFLP marker-based map of 18 LGs covering 1,400 cM (Spielmeyer et al. 1998), a 1,000 cM RFLP/ RAPD map with 94 markers assembled into 15 LGs (Oh et al. 2000) and a 113 marker map containing EST-SSRs, SNPs, genes and one phenotypic trait grouped into 24 LGs and spanning $834 \mathrm{cM}$ (Cloutier et al. 2011). Major QTL for fusarium wilt (Spielmeyer et al. 1998), for fatty acid composition and seed coat colour (Cloutier et al. 2011) were identified using these genetic maps. The increased marker density of the SU map from 113 (Cloutier et al. 2011) to 469 (this publication) significantly improved the map by bridging gaps and thereby reducing the number of LGs from 24 to 15 while increasing the map coverage from 834 to 3,044 cM which promises to enhance QTL detection. Collinearity with two additional genetic maps (BM and EV) further confirmed the accuracy of the groupings. The three maps were largely collinear with few marker inversions. Although some LGs or portions thereof were fixed in some of the individual populations (e.g. LG4, LG13 and LG15 in SU; LG7, LG9 and LG15 in BM; LG15 in EV), the consensus map successfully bridged LGs and resulted in good coverage across the genome with few gaps. Some local inconsistencies of marker order such as small inversions or local rearrangements between individual and consensus maps were observed, particularly in closely linked markers and markers located at the distal ends of LGs as previously reported for rye (Studer et al. 2010), cotton (Xu et al. 2008), Zoysia (Li et al. 2010), grapevine (Vezzulli et al. 2008) and Eucalyptus (Brondani et al. 2006). The single most striking discrepancy resided in the total length of the SU map which exceeded the size of the $\mathrm{BM}$ and $\mathrm{EV}$ maps by more than 1,000 cM. The higher

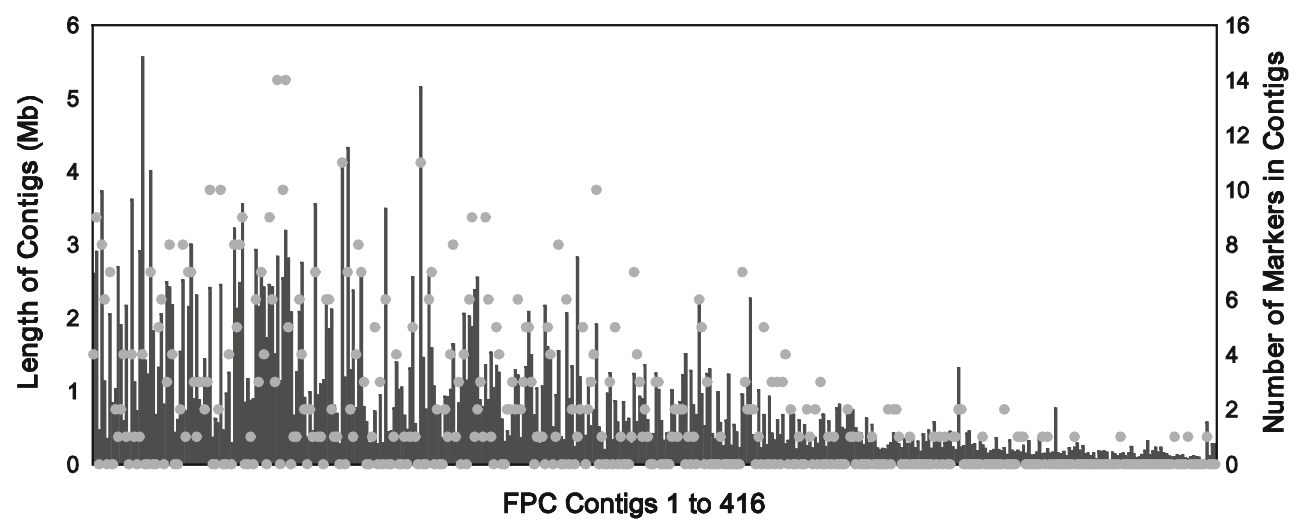

Fig. 2 Distribution of the genetic markers of the consensus map across the FPC contigs of the physical map (Ragupathy et al. 2011). A total of 204 of the 416 FPC contigs ( $x$ axis) were anchored by 670 marker loci (dots). The length of the contigs $(\mathrm{Mb})$ is on the left $y$ axis. From 1 to 14 marker loci (dots) were anchored onto each FPC contig represented on the right $y$ axis 
percentage $(36 \%)$ of distorted markers of this DH population, i.e. at least twice as high as the other two populations, may be responsible for the artifactual expansion of the genetic map length (Garcia-Dorado and Gallego 1992; Zhu et al. 2007; Li et al. 2011).

Comparative and consensus mapping are advantageous to obtain an unbiased linkage map representing the genome under investigation. As discussed above, mapping of markers employing multiple populations provides increased genome coverage because it is unlikely that multiple parents would all be fixed (monomorphic) in the same genomic regions. Also, overall population size afforded by multiple populations increases the chances of capturing recombination events, the foundation of genetic mapping. Reports of overrepresentation of localized crossover promoting 13mer motifs (Myers et al. 2008) in recombination hot spots of 1-2 kb (Ptak et al. 2005), and the influence of highly polymorphic trans-acting loci such as PRDM9 on the activation of those recombination hotspots in human (Baudat et al. 2010; Paigen and Petkov 2010) indicates the importance of the genomic background in crossover frequencies. Considering crossing over as a fundamental cellular process conserved across eukaryotes, variability for distribution of recombination hot spots and its genetic determinants can be determined using multiple populations. Comparative mapping can also offer evidence for duplications or chromosomal rearrangements (Sewell et al. 1999). As a consequence of merging of datasets from three populations, the consensus map had fewer and smaller gaps compared to the individual genetic maps, hence it was more comprehensive. Fatty acid desaturase genes $f a d 2 A, f a d 2 B, f a d 3 A$ and $f a d 3 B$, diacyl glycerol transferase genes dgat $A$ and $d g a t B$ and seed coat color gene yscl were positioned to seven different LGs of the consensus map. The majority were polymorphic in a single population but common neighbouring polymorphic markers permitted their integration in the consensus map, illustrating another advantage of consensus mapping. Flax has a relatively low level of genetic polymorphism, indicating a lower degree of genome divergence (Deng et al. 2010; Cloutier et al. 2011; Kale et al. 2012), unlike crops like maize where extensive molecular variation has been reported, primarily due to the activity of transposable elements (Llaca et al. 2011). The use of multiple populations followed by consensus mapping greatly increases marker saturation, a valuable feature for all mapping applications, for understanding the LD structure across genomes and germplasm characterization by association mapping (SotoCerda and Cloutier 2012).

The present consensus map of 770 SSR markers represents a major improvement over the low resolution phylogenetic analyses published to date with other marker types (McDill et al. 2009; Fu and Allaby 2010) and those published with few SSR markers within Linum usitatissimum (Wiesner et al. 2001; Cloutier et al. 2009) and across Linum species ( $\mathrm{Fu}$ and Peterson 2010; Soto-Cerda et al. 2011b). Pale flax (Linum bienne Mill, L. angustifolia Huds) is the wild progenitor of cultivated flax. Both have similar karyotypes bearing equal numbers of chromosomes $(2 \mathrm{n}=2 \mathrm{x}=30)$ (Muravenko et al. 2003) and interspecific crosses between them produce fertile progeny (Gill and Yermanos 1967; Diederichsen and Hammer 1995). Pale and cultivated flax have been inferred to differ by a single translocation event (Gill and Yermanos 1967). The exceptionally high transferability (97\%) of EST-SSRs from cultivated flax to L. bienne supports the assignment of pale flax to the primary gene pool (Diederichsen 2007; Fu and Peterson 2010; Soto-Cerda et al. 2011b). A genetic map for pale flax or an interspecific cross map has yet to be produced. The current availability of SSR markers combined with their cross applicability should allow for an indepth analysis of genetic diversity in L. bienne which should be useful to explore its potential to widen the gene pool of cultivated flax to meet breeding objectives.

Linum usitatissimum is a self-pollinated diploid species which, like a number of crop genomes, is an ancient polyploid (Blanc and Wolfe 2004; Paterson et al. 2004; Pfeil et al. 2005; Sterck et al. 2005; Gong et al. 2008; Soltis et al. 2009; Schmutz et al. 2010; Jiao et al. 2011; Lin and Paterson 2011). The remnant of ancestral whole genome duplication is reflected by the fact that a subset of SSR markers amplified two paralogous loci, although in most cases, only one was polymorphic (Cloutier et al. 2009, 2012). Mapping of the markers that amplified multiple polymorphic loci revealed ancestral chromosomal rearrangements resulting from paleopolyploidization events as noticed in LG6 and LG8. The existence of duplicated regions in consensus linkage groups LG6 and LG8 delimited by Lu2561 and Lu3057 markers indicate signatures of ancient duplication (Supplementary Figure 1). Analyses of a large collection of flax ESTs also corroborate the ancient duplication of flax (Venglat et al. 2011), as exemplified by the duplicate nature of the genes of the fatty acid biosynthetic pathway (Cloutier et al. 2011). Global comparative analysis of the scaffolds of the WGS sequence assembly promises a more comprehensive picture of the events that have shaped the flax genome through evolution.

\section{Distorted markers}

The segregation distortion in the three populations ranged from 15 to $36 \%$, an intermediate level, comparable to extent of distorted markers reported in common bean (37.3\%, de Campos et al. 2011), maize (19-36\%, Lu et al. 2002), red clover (5.8-45 \%, Isobe et al. 2009), Medicago truncatula (27\%, Thoquet et al. 2002) and peanut 
(8.5-22.8\%, Hong et al. 2010) but higher than C. pepo (3.7 \%, Zraidi et al. 2007; Gong et al. 2008), Brassica rapa (2.6\%, Song et al. 1991), grapevine (7-11\%, Doligez et al. 2006) and globe artichoke (13\%, Portis et al. 2009). Species such as Arabidopsis (43.0 \%, Reiter et al. 1992), cotton (71 \%, Lacape et al. 2009), tomato (68\%, Paterson et al. 1988), perennial ryegrass (32-63\%, Anhalt et al. 2008), Zoysia (43.7 \%, Li et al. 2010) and cowpea (41\%, Muchero et al. 2009), all displayed substantially higher percentages of markers deviating from the expected segregation ratios.

Non-Mendelian segregation ratios arise from chromosomal rearrangements, gametic competition, embryo viability and various physiological causes (Xu et al. 1997; Gonzalo et al. 2005; Portis et al. 2009) and, inadvertently, also from sampling errors (Lorieux et al. 2000). Segregation distortion has been associated more strongly with genetic effects as opposed to population structure or marker type (Anhalt et al. 2008).

Among the three flax populations reported here, the DH SU population had the highest proportion of distorted loci, similar to $\mathrm{DH}$ populations of rice $(31.8 \%, \mathrm{Xu}$ et al. 1997) and Brassica (22-49 \%, Wang et al. 2011), but lower than alfalfa (68\%, Li et al. 2011). The higher proportion of nonMendelian markers in DH populations may be attributed to selection for tissue culture responsiveness loci ( $\mathrm{Xu}$ et al. 1997; Alheit et al. 2011). Even though they were located on all LGs, distorted markers were not randomly distributed but were clustered within LGs (Cloutier et al. 2011; Córdoba et al. 2010; Li et al. 2011) supporting the cause of selection rather than experimental errors (Li et al. 2011), a view further emphasized by higher proportions of distorted markers on specific LGs such as LG2 (36/65), LG8 (52/68) and LG10 (32/46). Chromosome specific uneven distribution of markers has been reported for triticale chromosome 2A and 1R (Alheit et al. 2011); LG1, LG2 and LG3 of Medicago truncatula (Studer et al. 2010) and M20 and M32 of Zoysia (Li et al. 2010). Clustering of distorted markers was also documented in lettuce (Truco et al. 2007), Eucalyptus (Brondani et al. 2006) and peanut (Hong et al. 2010).

Map distance and map order can both be affected by segregation distortion (Lyttle 1991; Zhu et al. 2007) as was observed in the SU population where large gaps were observed between blocks of non-Mendelian markers adjacent to blocks of markers with non-skewed segregation, which accounted in part for the overestimation of the map length for this population. Elimination of non-Mendelian marker loci was suggested to improve mapping accuracies (Zhu et al. 2007; Xu 2008). However, such an approach would decrease the number of markers available and reduce coverage of some genomic regions, hence diminishing the map saturation (Zhu et al. 2007; Xu 2008). Here, we clearly demonstrated that consensus mapping was a powerful way to correct for mapping inaccuracies caused by non-Mendelian markers because consensus mapping takes into account segregation data from multiple populations including common markers with Mendelian segregation in at least one population.

Anchoring genetic and physical maps

The physical map of flax is comprised of 416 FPC contigs spanning $\sim 368 \mathrm{Mb}$ (Ragupathy et al. 2011). A total of 670 markers were anchored to 204 FPC contigs representing $\sim 274 \mathrm{Mb}$, i.e. $74 \%$ of the estimated $370 \mathrm{Mb}$ genome of CDC Bethune, comparable to papaya (72.4\%, Yu et al. 2009), apple (60\%, Han et al. 2011) and grapevine (72\%, Scalabrin et al. 2010) genomes and exceeding the extent of anchoring reported in Medicago truncatula (32\%, Mun et al. 2006), Populus trichocarpa (22\%, Kelleher et al. 2007), Prunus (15.5\%, Zhebentyayeva et al. 2008), bean (8\%, Córdoba et al. 2010) and melon (12\%, González et al. 2010). Although sufficient to provide initial ordering of the WGS sequence assembly into bins, the level of anchoring of the physical and genetic maps of flax presented herein falls short of the requirement for high accuracy ordering and orienting of the scaffolds of genomic sequence as was shown in maize (93\%, Wei et al. 2009) and rice (91\%, Chen et al. 2002). Tens of thousands of genome-wide SNPs currently being developed in our lab from the three mapping populations, using the state of the art 'genotyping by sequencing (GBS)' approach (Davey et al. 2011) will likely provide the degree of saturation necessary for the task of obtaining an accurate physical map ordering and orientation, a prerequisite for a high quality genome sequence assembly.

In conclusion, we reported on the construction of the first consensus genetic map of flax using 411 individuals from three populations and grouping and ordering 770 markers in 15 LGs spanning 1,551 cM. The vast majority of the markers are SSRs, a highly reproducible marker system which should prove its usefulness as an important resource for the flax research community, especially flax breeders. The overall map density averaged one marker every $2.0 \mathrm{cM}$. The consensus genetic map has been anchored to the flax physical map, a first step in the ordering of the scaffolds that currently make up the WGS sequence assembly of the flax genome. This integrated map will enable structural and functional genomic studies including fine mapping of genes of interest, marker-assisted flax breeding, map-based gene cloning, comparative/ synteny mapping, QTL analysis and association mapping in flax and other related species.

Acknowledgments We sincerely thank Rae-Ann Trudeau for technical assistance, Joanne Schiavoni for manuscript editing and 
Michael Shillinglaw for figure preparation. This research is part of the Total Utilization Flax GENomics (TUFGEN) project funded by Genome Canada and co-funded in part by the Agriculture Development Fund of Saskatchewan, the Governments of Manitoba and Saskatchewan, the Flax Council of Canada and the Manitoba Flax Growers Association. Project management and support by Genome Prairie are also acknowledged.

Open Access This article is distributed under the terms of the Creative Commons Attribution License which permits any use, distribution, and reproduction in any medium, provided the original author(s) and the source are credited.

\section{References}

Adugna W, Labuschagne MT, Viljoen CD (2006) The use of morphological and AFLP markers in diversity analysis of linseed. Biodivers Conserv 15:3193-3205

Alheit KV, Reif JC, Maurer HP, Hahn V, Weissmann EA, Miedaner T, Würschum $T$ (2011) Detection of segregation distortion loci in triticale (x Triticosecale Wittmack) based on a high-density DArT marker consensus genetic linkage map. BMC Genomics 12:380

Anhalt UCM, Heslop-Harrison PJS, Byrne S, Guillard A, Barth S (2008) Segregation distortion in Lolium: evidence for genetic effects. Theor Appl Genet 117:297-306

Antonio BA, Inoue T, Kajiya H, Nagamura Y, Kurata N, Minobe Y, Yano M, Nakagahra M, Sasaki T (1996) Comparison of genetic distance and order of DNA markers in five populations of rice. Genome 39:946-956

Ball AD, Stapley J, Dawson DA, Birkhead TR, Burke T, Slate J (2010) A comparison of SNPs and microsatellites as linkage mapping markers: lessons from the zebra finch (Taeniopygia guttata). BMC Genomics 11:218

Banik M, Duguid S, Cloutier S (2011) Transcript profiling and gene characterization of three fatty acid desaturase genes in high, moderate, and low linolenic acid genotypes of flax (Linum usitatissimum L.) and their role in linolenic acid accumulation. Genome 54:471-483

Baudat F, Buard J, Grey C, Fledel-Alon A, Ober C, Przeworski M, Coop G, de Massy B (2010) PRDM9 is a major determinant of meiotic recombination hotspots in humans and mice. Science 327:836-840

Bickel CL, Gadani S, Lukacs M, Cullis CA (2011) SSR markers developed for genetic mapping in flax (Linum usitatissimum L.). Res Rep Biol 2011:23-29

Blanc G, Wolfe KH (2004) Widespread paleopolyploidy in model plant species inferred from age distributions of duplicate genes. Plant Cell 16:1667-1678

Brondani RPV, Williams ER, Brondani C, Grattapaglia D (2006) A microsatellite-based consensus linkage map for species of Eucalyptus and a novel set of 230 microsatellite markers for the genus. BMC Plant Biol 6:20

Chen M, Presting G, Barbazuk WB, Goicoechea JL, Blackmon B, Fang G, Kim H, Frisch D, Yu Y, Sun S, Higingbottom S, Phimphilai J, Phimphilai D, Thurmond S, Gaudette B, Li P, Liu J, Hatfield J, Main D, Farrar K, Henderson C, Barnett L, Costa R, Williams B, Walser S, Atkins M, Hall C, Budiman MA, Tomkins JP, Luo M, Bancroft I, Salse J, Regad F, Mohapatra T, Singh NK, Tyagi AK, Soderlund C, Dean RA, Wing RA (2002) An integrated physical and genetic map of the rice genome. Plant Cell 14:537-545

Cheng X, Xu J, Xia S, Gu J, Yang YF, Fu J, Qian X, Zhang S, Wu J, Liu K (2009) Development and genetic mapping of microsatellite markers from genome survey sequences in Brassica napus. Theor Appl Genet 118:1121-1131

Cloutier S, Niu Z, Datla R, Duguid S (2009) Development and analysis of EST-SSRs for flax (Linum usitatissimum L.). Theor Appl Genet 119:53-63

Cloutier S, Ragupathy R, Niu Z, Duguid S (2011) SSR-based linkage map of flax (Linum usitatissimum L.) and mapping of QTLs underlying fatty acid composition traits. Mol Breeding 28:437-451

Cloutier S, Miranda E, Ward K, Radovanovic N, Reimer E, Walichnowski A, Datla R, Rowland G, Duguid S, Ragupathy R (2012) Simple sequence repeat marker development from bacterial artificial chromosome end sequences and expressed sequence tags of flax (Linum usitatissimum L.). Theor Appl Genet 125:685-694

Collard BCY, Jahufer MZZ, Brouwer JB, Pang ECK (2005) An introduction to markers, quantitative trait loci (QTL) mapping and marker-assisted selection for crop improvement: the basic concepts. Euphytica 142:169-196

Cone KC, McMullen MD, Bi IV, Davis GL, Yim YS, Gardiner JM, Polacco ML, Sanchez-Villeda H, Fang Z, Schroeder SG, Havermann SA, Bowers JE, Paterson AH, Soderlund CA, Engler FW, Wing RA, Coe EH Jr (2002) Genetic, physical, and informatics resources for maize. On the road to an integrated map. Plant Physiol 130:1598-1605

Córdoba JM, Chavarro C, Schlueter JA, Jackson SA, Blair MW (2010) Integration of physical and genetic maps of common bean through BAC-derived microsatellite markers. BMC Genomics 11:436

Danan S, Veyrieras J-B, Lefebvre V (2011) Construction of a potato consensus map and QTL meta-analysis offer new insights into the genetic architecture of late blight resistance and plant maturity traits. BMC Plant Biol 11:16

Davey JW, Hohenlohe PA, Etter PD, Boone JQ, Catchen JM, Blaxter ML (2011) Genome-wide genetic marker discovery and genotyping using next-generation sequencing. Nat Rev Genet 12:499-510

de Campos T, Oblessuc PR, Sforça DA, Cardoso JMK, Baroni RM, de Sousa ACB, Carbonell SAM, Chioratto AF, Garcia AAF, Rubiano LB, de Souza AP (2011) Inheritance of growth habit detected by genetic linkage analysis using microsatellites in the common bean (Phaseolus vulgaris L.). Mol Breeding 27:549-560

Deng X, Long SH, He DF, Li X, Wang YF, Liu J, Chen XB (2010) Development and characterization of polymorphic microsatellite markers in Linum usitatissmum. J Plant Res 123:119-123

Deng X, Long SH, He DF, Li X, Wang YF, Hao DM, Qiu CS, Chen $\mathrm{XB}$ (2011) Isolation and characterization of polymorphic microsatellite markers from flax (Linum usitatissimum L.). Afr J Biotechnol 10:734-739

Diaz A, Fergany M, Formisano G, Ziarsolo P, Blanca J, Fei Z, Staub JE, Zalapa JE, Cuevas HE, Dace G, Oliver M, Boissot N, Dogimont C, Pitrat M, Hofstede R, van Koert P, Harel-Beja R, Tzuri G, Portnoy V, Cohen S, Schaffer A, Katzir N, Xu Y, Zhang H, Fukino N, Matsumoto S, Garcia-Mas J, Monforte AJ (2011) A consensus linkage map for molecular markers and quantitative trait loci associated with economically important traits in melon (Cucumis melo L.). BMC Plant Biol 11:111

Diederichsen A (2001) Comparison of genetic diversity of flax (Linum usitatissimum L.) between Canadian cultivars and a world collection. Plant Breed 120:360-362

Diederichsen A (2007) Ex-situ collections of cultivated flax (Linum usitatissimum L.) and other species of the genus Linum L. Genet Resour Crop Evol 54:661-678

Diederichsen A, Hammer K (1995) Variation of cultivated flax (Linum usitatissimum L. subsp. usitatissimum) and its wild 
progenitor pale flax (subsp. angustifolium (Huds.) Thell.). Genet Resour Crop Evol 42:263-272

Diederichsen A, Raney JP (2006) Seed colour, seed weight and seed oil content in Linum usitatissimum accessions held by plant gene resources of Canada. Plant Breed 125:372-377

Doligez A, Adam-Blondon AF, Cipriani G, Di Gaspero G, Laucou V, Merdinoglu D, Meredith CP, Riaz S, Roux C, This P (2006) An integrated SSR map of grapevine based on five mapping populations. Theor Appl Genet 113:369-382

Fu YB (2006) Redundancy and distinctness in flax germplasm as revealed by RAPD dissimilarity. Plant Genet Resour 4:117-124

Fu YB, Allaby RG (2010) Phylogenetic network of Linum species as revealed by non-coding chloroplast DNA sequences. Genet Resour Crop Evol 57:667-677

Fu YB, Peterson GW (2010) Characterization of expressed sequence tag-derived simple sequence repeat markers for 17 Linum species. Bot 88:537-543

Fu YB, Rowland GG, Duguid SD, Richards KW (2003) RAPD analysis of 54 North American flax cultivars. Crop Sci 43:1510-1515

Garcia-Dorado A, Gallego A (1992) On the use of classical tests for detecting linkage. J Heredity 83:143-146

Gill KS (1987) Linseed. Publications and Information Division. Indian Council of Agricultural Research, New Delhi, p 386

Gill KS, Yermanos DM (1967) Cytogenetic studies on the genus Linum I. Hybrids among taxa with 15 as the haploid chromosome number. Crop Sci 7:623-627

Gong L, Stift G, Kofler R, Pachner M, Lelley T (2008) Microsatellites for the genus Cucurbita and an SSR-based genetic linkage map of Cucurbita pepo L. Theor Appl Genet 117:37-48

González VM, Garcia-Mas J, Arús P, Puigdomènech P (2010) Generation of a BAC-based physical map of the melon genome. BMC Genomics 11:339

Gonzalo MJ, Oliver M, Garcia-Mas J, Monforte AJ, Dolcet-Sanjuan R, Katzir N, Arus P, Monforte A (2005) Simple-sequence repeat markers used in merging linkage maps of melon (Cucumis melo L.). Theor Appl Genet 110:802-811

Gu YQ, Ma Y, Huo N, Vogel JP, You FM, Lazo GR, Nelson WM, Soderlund C, Dvorak J, Anderson OD, Luo M-C (2009) A BACbased physical map of Brachypodium distachyon and its comparative analysis with rice and wheat. BMC Genomics 10:496

Gustafson JP, Ma X-F, Korzun V, Snape JW (2009) A consensus map of rye integrating mapping data from five mapping populations. Theor Appl Genet 118:793-800

Han Y, Zheng D, Vimolmangkang S, Khan MA, Beever JE, Korban SS (2011) Integration of physical and genetic maps in apple confirms whole-genome and segmental duplications in the apple genome. J Exp Bot 62:5117-5130

Hauge BM, Hanley SM, Cartinhour S, Cherry JM, Goodman HM (1993) An integrated genetic/RFLP map of the Arabidopsis thaliana genome. Plant J 3:745-754

Hong Y, Chen X, Liang X, Liu H, Zhou G, Li S, Wen S, Holbrook CC, Guo B (2010) A SSR-based composite genetic linkage map for the cultivated peanut (Arachis hypogaea L.) genome. BMC Plant Biol 10:17

Hwang T-Y, Sayama T, Takahashi M, Takada Y, Nakamoto Y, Funatsuki H, Hisano H, Sasamoto S, Sato S, Tabata S, Kono I, Hoshi M, Hanawa M, Yano C, Xia Z, Harada K, Kitamura K, Ishimoto M (2009) High-density integrated linkage map based on SSR markers in soybean. DNA Res 16:213-225

Isobe S, Kölliker R, Hisano H, Sasamoto S, Wada T, Klimenko I, Okumura K, Tabata S (2009) Construction of a consensus linkage map for red clover (Trifolium pratense L.). BMC Plant Biol 9:57
Jiao Y, Wickett NJ, Ayyampalayam S, Chanderbali AS, Landherr L, Ralph PE, Tomsho LP, Hu Y, Liang H, Soltis PS, Soltis DE, Clifton SW, Schlarbaum SE, Schuster SC, Ma H, Leebens-Mack L, dePamphilis CW (2011) Ancestral polyploidy in seed plants and angiosperms. Nature 473:97-100

Kale SM, Pardeshi VC, Kadoo NY, Ghorpade PB, Jana MM, Gupta VS (2012) Development of genomic simple sequence repeat markers for linseed using next-generation sequencing technology. Mol Breeding 30:597-606

Kelleher CT, Chiu R, Shin H, Bosdet IE, Krzywinski MI, Fjell CD, Wilkin J, Yin TM, DiFazio SP, Ali J, Asano JK, Chan S, Cloutier A, Grin N, Leach S, Lee D, Mathewson CA, Olson T, O'Connor K, Prabhu AL, Smailus DE, Stott JM, Tsai M, Wye NH, Yang GS, Zhuang J, Holt RA, Putnam NH, Vrebalov J, Giovannoni JJ, Grinwood J, Schmutz J, Rokhsar D, Jones SJM, Marra MA, Tuskan GA, Bohlmann J, Ellis BE, Ritland K, Douglas CJ, Schein JE (2007) A physical map of the highly heterozygous Populus genome: integration with the genome sequence and genetic map and analysis of haplotype variation. Plant J 50:1063-1078

Kosambi DD (1944) The estimation of map distance from recombination values. Ann Eugen 12:172-175

Lacape J-M, Jacobs J, Arioli T, Derijcker R, Forestier-Chiron N, Llewellyn D, Jean J, Thomas E, Viot C (2009) A new interspecific, Gossypium hirsutum X G. barbadense, RIL population: towards a unified consensus linkage map of tetraploid cotton. Theor Appl Genet 119:281-292

Langridge P, Karakousis A, Collins N, Kretschmer J, Manning S (1995) A consensus linkage map of barley. Mol Breeding 1:389-395

Li M, Yuyama N, Hirata M, Wang Y, Han J, Cai H (2010) An integrated SSR based linkage map for Zoysia matrella $\mathrm{L}$. and $Z$. japonica Steud. Mol Breeding 26:467-476

Li X, Wang X, Wei Y, Brummer EC (2011) Prevalence of segregation distortion in diploid alfalfa and its implications for genetics and breeding applications. Theor Appl Genet 123:667-679

Lin L, Paterson AH (2011) Size variation in homologous segments across divergent plant genomes. Mob Genet Elements 1:92-96

Llaca V, Campbell MA, Deschamps S (2011) Genome diversity in maize. J Bot. doi:10.1155/2011/104172

Lorieux M, Ndjiondjop M-N, Ghesquière A (2000) A first interspecific Oryza sativa X $O$. glaberrima microsatellite-based genetic linkage map. Theor Appl Genet 100:593-601

Lu H, Romero-Severson J, Bernardo R (2002) Chromosomal regions associated with segregation distortion in maize. Theor Appl Genet 105:622-628

Lyttle TW (1991) Segregation distorters. Annu Rev Genet 25:511-555

Mace ES, Rami J-F, Bouchet S, Klein PE, Klein RR, Kilian A, Wenzl P, Xia L, Halloran K, Jordan DR (2009) A consensus genetic map of sorghum that integrates multiple component maps and high-throughput Diversity Array Technology (DArT) markers. BMC Plant Biol 9:13

Marchenkov A, Rozhmina T, Uschapovsky I, Muir AD (2003) Cultivation of flax. In: Muir AD, Westcott ND (eds) Flax: the genus Linum. CRC, New York, pp 74-91

McDill J, Repplinger M, Simpson BB, Kadereit JW (2009) The phylogeny of Linum and Linaceae subfamily Linoideae, with implications for their systematics, biogeography, and evolution of heterostyly. Syst Bot 34:386-405

Messing J, Bharti AK, Karlowski WM, Gundlach H, Kim HR, Yu Y, Wei F, Fuks G, Soderlund CA, Mayer KFX, Wing RA (2004) Sequence composition and genome organization of maize. Proc Natl Acad Sci USA 101:14349-14354

Millan T, Winter P, Jüngling R, Gil J, Rubio J, Cho S, Cobos MJ, Iruela M, Rajesh PN, Tekeoglu M, Kahl G, Muehlbauer FJ 
(2010) A consensus genetic map of chickpea (Cicer arietinum L.) based on 10 mapping populations. Euphytica 175:175-189

Mozo T, Dewar K, Dunn P, Ecker JR, Fischer S, Kloska S, Lehrach H, Marra M, Martienssen R, Meier-Ewert S, Altmann T (1999) A complete BAC-based physical map of the Arabidopsis thaliana genome. Nat Genet 22:271-275

Muchero W, Diop NN, Bhat PR, Fenton RD, Wanamaker S, Pottorff M, Hearne S, Cisse N, Fatokun C, Ehlers JD, Roberts PA, Close TJ (2009) A consensus genetic map of cowpea [Vigna unguiculata (L) Walp.] and synteny based on EST-derived SNPs. Proc Natl Acad Sci USA 106:18159-18164

Mun J-H, Kim D-J, Choi H-K, Gish J, Debellé F, Mudge J, Denny R, Endré G, Saurat O, Dudez A-M, Kiss GB, Roe B, Young ND, Cook DR (2006) Distribution of microsatellites in the genome of Medicago truncatula: a resource of genetic markers that integrate genetic and physical maps. Genetics 172:2541-2555

Mun J-H, Kwon S-J, Yang T-J, Kim H-S, Choi B-S, Baek S, Kim JS, Jin M, Kim JA, Lim M-H, Lee SI, Kim H-I, Kim H, Lim YP, Park B-S (2008) The first generation of a BAC-based physical map of Brassica rapa. BMC Genomics 9:280

Muravenko OV, Lemesh VA, Samatadze TE, Amosova AV, Grushetskaya ZE, Popov KV, Semenova OYu, Khotuyleya LV, Zelenin AV (2003) Genome comparisons with chromosomal and molecular markers for three closely related flax species and their hybrids. Russ J Genet 39:414-422

Myers S, Freeman C, Auton A, Donnelly P, McVean G (2008) A common sequence motif associated with recombination hot spots and genome instability in humans. Nat Genet 40:1124-1129

Oh TJ, Gorman M, Cullis CA (2000) RFLP and RAPD mapping in flax (Linum usitatissimum). Theor Appl Genet 101:590-593

Paigen K, Petkov P (2010) Mammalian recombination hot spots: properties, control and evolution. Nat Rev Genet 11:221-233

Paterson AH, Lander ES, Hewitt JD, Peterson S, Lincoln SE, Tanksley SD (1988) Resolution of quantitative traits into Mendelian factors by using a complete linkage map of restriction fragment length polymorphisms. Nature 335:721-726

Paterson AH, Bowers JE, Chapman BA (2004) Ancient polyploidization predating divergence of the cereals, and its consequences for comparative genomics. Proc Natl Acad Sci USA 101:9903-9908

Pfeil BE, Schlueter JA, Shoemaker RC, Doyle JJ (2005) Placing paleopolyploidy in relation to taxon divergence: a phylogenetic analysis in legumes using 39 gene families. Syst Biol $54: 441-454$

Portis E, Mauromicale G, Mauro R, Acquadro A, Scaglione D, Lanteri S (2009) Construction of a reference molecular linkage map of globe artichoke (Cynara cardunculus var. scolymus). Theor Appl Genet 120:59-70

Powell W, Machray GC, Provan J (1996) Polymorphism revealed by simple sequence repeats. Trends Plant Sci 1:215-222

Ptak SE, Hinds DA, Koehler K, Nickel B, Patil N, Ballinger DG, Przeworski M, Frazer KA, Pääbo S (2005) Fine-scale recombination patterns differ between chimpanzees and humans. Nat Genet 37:429-434

Rachinskaya OA, Lemesh VA, Muravenko OV, Yurkevich OYu, Guzenko EV, Bol'sheva NL, Bogdanova MV, Samatadze TE, Popov KV, Malyshev SV, Shostak NG, Heller K, Hotyleva LV, Zelenin AV (2011) Genetic polymorphism of flax Linum usitatissimum based on the use of molecular cytogenetic markers. Russ J Genet 47:56-65

Ragupathy R, Rathinavelu R, Cloutier S (2011) Physical mapping and $\mathrm{BAC}$-end sequence analysis provide initial insights into the flax (Linum usitatissimum L.) genome. BMC Genomics 12:217

Reiter RS, Williams JG, Feldmann KA, Rafalski JA, Tingey SV, Scolnik PA (1992) Global and local genome mapping in Arabidopsis thaliana by using recombinant inbred lines and random amplified polymorphic DNAs. Proc Natl Acad Sci USA 89:1477-1481

Roose-Amsaleg C, Cariou-Pham E, Vautrin D, Tavernier R, Solignac M (2006) Polymorphic microsatellite loci in Linum usitatissimum. Mol Ecol Notes 6:796-799

Saeidi G (2008) Genetic variation and heritability for germination, seed vigour and field emergence in brown and yellow-seeded genotypes of flax. Int J Plant Prod 2:15-22

Scalabrin S, Troggio M, Moroldo M, Pindo M, Felice N, Coppola G, Prete G, Malacarne G, Marconi R, Faes G, Jurman I, Grando S, Jesse T, Segala C, Valle G, Policriti A, Fontana P, Morgante M, Velasco R (2010) Physical mapping in highly heterozygous genomes: a physical contig map of the Pinot Noir grapevine cultivar. BMC Genomics 11:204

Schmutz J, Cannon SB, Schlueter J, Ma J, Mitros T, Nelson W, Hyten DL, Song Q, Thelen JJ, Cheng J, Xu D, Hellsten U, May GD, Yu Y, Sakurai T, Umezawa T, Bhattacharyya MK, Sandhu D, Valliyodan B, Lindquist E, Peto M, Grant D, Shu S, Goodstein D, Barry K, Futrell-Griggs M, Abernathy B, Du J, Tian Z, Zhu L, Gill N, Joshi T, Libault M, Sethuraman A, Zhang X-C, Shinozaki K, Nguyen HT, Wing RA, Cregan P, Specht J, Grimwood J, Rokhsar D, Stacey G, Shoemaker RC, Jackson SA (2010) Genome sequence of the paleopolyploid soybean. Nature 463:178-183

Sewell MM, Sherman BK, Neale DB (1999) A consensus map for loblolly pine (Pinus taeda L.). I. Construction and integration of individual linkage maps from two outbred three-generation pedigrees. Genetics 151:321-330

Soltis DE, Albert VA, Leebens-Mack J, Bell CD, Paterson AH, Zheng C, Sankoff D, dePamphilis CW, Wall PK, Soltis PS (2009) Polyploidy and angiosperm diversification. Am J Bot 96:336-348

Somers DJ, Isaac P, Edwards K (2004) A high-density microsatellite consensus map for bread wheat (Triticum aestivum L.). Theor Appl Genet 109:1105-1114

Song KM, Suzuki JY, Slocum MK, Williams PH, Osborn TC (1991) A linkage map of Brassica rapa (syn. campestris) based on restriction fragment length polymorphism loci. Theor Appl Genet 82:296-304

Soto-Cerda BJ, Cloutier S (2012) Association mapping in plant genomes. In: Caliskan M (ed) Genetic diversity in plants. InTech, Rijeka, pp 29-54

Soto-Cerda BJ, Carrasco RA, Aravena GA, Urbina HA, Navarro CS (2011a) Identifying novel polymorphic microsatellites from cultivated flax (Linum usitatissimum L.) following data mining. Plant Mol Biol Rep 29:753-759

Soto-Cerda BJ, Urbina Saavedra H, Navarro Navarro C, Mora Ortega P (2011b) Characterization of novel genic SSR markers in Linum usitatissimum (L.) and their transferability across eleven Linum species. Electronic J Biotechnol 14:6

Spielmeyer W, Green AG, Bittisnich D, Mendham N, Lagudah ES (1998) Identification of quantitative trait loci contributing to Fusarium wilt resistance on an AFLP linkage map of flax (Linum usitatissimum). Theor Appl Genet 97:633-641

Stam P (1993) Construction of integrated genetic linkage maps by means of a new computer package: JoinMap. Plant J 3:739-744

Sterck L, Rombauts S, Jansson S, Sterky F, Rouzé P, Van de Peer Y (2005) EST data suggest that poplar is an ancient polyploid. New Phytol 167:165-170

Studer B, Kölliker R, Muylle H, Asp T, Frei U, Roldán-Ruiz I, Barre P, Tomaszewski C, Meally H, Barth S, Skøt L, Armstead IP, Dolstra O, Lübberstedt T (2010) EST-derived SSR markers used as anchor loci for the construction of a consensus linkage map in ryegrass (Lolium spp.). BMC Plant Biol 10:177

Thoquet P, Ghérardi M, Journet E-P, Kereszt A, Ané J-M, Prosperi J-M, Huguet T (2002) The molecular genetic linkage map of the 
model legume Medicago truncatula: an essential tool for comparative legume genomics and the isolation of agronomically important genes. BMC Plant Biol 2:1

Truco MJ, Antonise R, Lavelle D, Ochoa O, Kozik A, Witsenboer H, Fort SB, Jeuken MJW, Kesseli RV, Lindhout P, Michelmore RW, Peleman J (2007) A high-density, integrated genetic linkage map of lettuce (Lactuca spp.). Theor Appl Genet 115:735-746

Uysal H, Fu Y-B, Kurt O, Peterson GW, Diederichsen A, Kusters P (2010) Genetic diversity of cultivated flax (Linum usitatissimum L.) and its wild progenitor pale flax (Linum bienne Mill.) as revealed by ISSR markers. Genet Resour Crop Evol 57:1109-1119

Van Ooijen JW (2006) JoinMap ${ }^{\circledR} 4.0$, Software for the calculation of genetic linkage maps in experimental populations. Kyazma B.V., Wageningen, Netherlands

Varshney RK, Sigmund R, Borner A, Korzun V, Stein N, Sorrells ME, Langridge P, Graner A (2005) Interspecific transferability and comparative mapping of barley EST-SSR markers in wheat, rye and rice. Plant Sci 168:195-202

Varshney RK, Marcel TC, Ramsay L, Russell J, Röder MS, Stein N, Waugh R, Langridge P, Niks RE, Graner A (2007) A high density barley microsatellite consensus map with 775 SSR loci. Theor Appl Genet 114:1091-1103

Venglat P, Xiang D, Qiu S, Stone SL, Tibiche C, Cram D, AltingMees M, Nowak J, Cloutier S, Deyholos M, Bekkaoui F, Sharpe A, Wang E, Rowland G, Selvaraj G, Datla R (2011) Gene expression analysis of flax seed development. BMC Plant Biol 11:74

Vezzulli S, Troggio M, Coppola G, Jermakow A, Cartwright D, Zharkikh A, Stefanini M, Grando MS, Viola R, Adam-Blondon AF, Thomas M, This P, Velasco R (2008) A reference integrated map for cultivated grapevine (Vitis vinifera L.) from three crosses, based on 283 SSR and 501 SNP-based markers. Theor Appl Genet 117:499-511

Wang J, Lydiate DJ, Parkin IAP, Falentin C, Delourme R, Carion PWC, King GJ (2011) Integration of linkage maps for the Amphidiploid Brassica napus and comparative mapping with Arabidopsis and Brassica rapa. BMC Genomics 12:101

Wei F, Zhang J, Zhou S, He R, Schaeffer M, Collura K, Kudrna D, Faga BP, Wissotski M, Golser W, Rock SM, Graves TA, Fulton RS, Coe E, Schnable PS, Schwartz DC, Ware D, Clifton SW,
Wilson RK, Wing RA (2009) The physical and genetic framework of the maize B73 genome. PLoS Genet 5(11):e1000715

Wiesner I, Wiesnerova D, Tejklova E (2001) Effect of anchor and core sequence in microsatellite primers on flax fingerprinting patterns. J Agric Sci 137:37-44

Wu C, Sun S, Nimmakayala P, Santos FA, Meksem K, Springman R, Ding K, Lightfoot DA, Zhang H-B (2004) A BAC- and BIBACbased physical map of the soybean genome. Genome Res 14:319-326

Xu S (2008) Quantitative trait locus mapping can benefit from segregation distortion. Genetics 180:2201-2208

Xu Y, Zhu L, Xiao J, Huang N, McCouch SR (1997) Chromosomal regions associated with segregation distortion of molecular markers in $F_{2}$, backcross, doubled haploid, and recombinant inbred populations in rice (Oryza sativa L.). Mol Gen Genet 253:535-545

Xu Z, Kohel RJ, Song G, Cho J, Yu J, Yu S, Tomkins J, Yu JZ (2008) An integrated genetic and physical map of homoeologous chromosomes 12 and 26 in Upland cotton ( $G$. hirsutum L.). BMC Genomics 9:108

Xu J, Qian X, Wang X, Li R, Cheng X, Yang Y, Fu J, Zhang S, King GJ, Wu J, Liu K (2010) Construction of an integrated genetic linkage map for the A genome of Brassica napus using SSR markers derived from sequenced BACs in B. rapa. BMC Genomics 11:594

Yu Q, Tong E, Skelton RL, Skelton RL, Bowers JE, Jones MR, Murray JE, Hou S, Guan P, Acob RA, Luo M-C, Moore PH, Alam M, Paterson AH, Ming R (2009) A physical map of the papaya genome with integrated genetic map and genome sequence. BMC Genomics 10:371

Zhebentyayeva TN, Swire-Clark G, Georgi LL, Garay L, Jung S, Forrest S, Blenda AV, Blackmon B, Mook J, Horn R, Howad W, Arús P, Main D, Tomkins JP, Sosinski B, Baird WV, Reighard GL, Abbott AG (2008) A framework physical map for peach, a model Rosaceae species. Tree Genet Genomes 4:745-756

Zhu C, Wang C, Zhang Y-M (2007) Modeling segregation distortion for viability selection I. Reconstruction of linkage maps with distorted markers. Theor Appl Genet 114:295-305

Zraidi A, Stift G, Pachner M, Shojaeiyan A, Gong L, Lelley T (2007) A consensus map for Cucurbita pepo. Mol Breeding 20:375-388 